\section{Dousing diabetes' flames}

\section{By Lev Osherovich, Senior Writer}

Four papers in Nature Medicine paint a picture of adipose tissue inflammation as the bridge between obesity and insulin resistance, a hallmark of type 2 diabetes. ${ }^{1-4}$ The findings argue for treating the disease with $\mathrm{mAbs}$ for $\mathrm{CD} 3$, a target on $\mathrm{T}$ cells that is already being pursued in type 1 diabetes by Tolerx Inc., MacroGenics Inc. and others.

Two of the studies were from separate teams at Harvard Medical School. The other two were led by researchers from the University of Toronto and The University of Tokyo.

Previous research has implicated macrophages and other innate immune cells as biomarkers of metabolic disease, ${ }^{5}$ but the specific roles of these cells in the transition from obesity to full-blown type 2 diabetes was mysterious.

"Our studies started with the observations in the literature that there are a lot of macrophages and inflammation in the adipose tissue of obese individuals," said Diane Mathis, professor of pathology at Harvard Medical School and senior author on one of the studies. " We wondered why some of the mechanisms in controlling macrophages were not coming into play in obesity."

Mathis' team examined the immune cell composition of murine adipose tissue and found that nonobese wild-type mice had high levels of $\mathrm{T}_{\text {reg }}$ cells, which suppress immune cell recruitment and activation.

However, in three different mouse models of obesity, $\mathrm{T}_{\text {reg }}$ levels in fat tissue were lower than those in nonobese wild-type mice. "When we looked in the adipose tissue of obese mice, we found that these $T_{\text {regs }}$ are essentially gone," noted Mathis.

Her group manipulated fat tissue $\mathrm{T}_{\text {reg }}$ levels with conditional knockouts, cell transfers and antibody experiments and found that $\mathrm{T}_{\text {regs }}$ ordinarily prevented fat inflammation. Indeed, obese mice treated with an immunotherapeutic complex known to raise $\mathrm{T}_{\text {reg }}$ levels showed less inflammation and better glucose tolerance than mock-treated mice.

Mathis has patented her team's discoveries and now plans to define the mechanism by which $\mathrm{T}_{\text {regs }}$ suppress the progression to type 2 diabetes.

\section{T for two}

Although it's unclear what causes $\mathrm{T}_{\text {regs }}$ to migrate from adipose tissue in obese animals, one clue comes from a study by Canadian researchers that suggests that $\mathrm{T}$ helper type 1 (Th1) cells could be responsible for the low levels of $\mathrm{T}_{\text {regs }}{ }^{2}$

A team led by Hans-Michael Dosch isolated $\mathrm{T}$ cells from adipose tissue of lean and obese mice and humans. $\mathrm{T}_{\text {reg }}$ levels fell in obese tissue, but Th1 cell levels rose compared with those in lean controls. Dosch is a professor of immunology and pediatrics at the University of Toronto and a senior scientist at The Hospital for Sick Children.

To test whether Th1 cells were responsible for the drop in adipose $\mathrm{T}_{\text {reg }}$ levels and the resulting metabolic dysregulation, Dosch's team treated obese mice with an antibody against the $\mathrm{T}$ cell co-receptor CD3 - a treatment that depleted Th1 cells but left $\mathrm{T}_{\text {regs }}$ intact.

The antibody raised $\mathrm{T}_{\text {reg }}$ levels to near those in lean mice and improved glucose tolerance and insulin sensitivity compared with a control antibody.

Dosch thinks his team's conclusions are "astoundingly similar" to those of Mathis and that the findings collectively point to immunological regulation of the progression from obesity to type 2 diabetes.

He also noted that many of the immune cells implicated in obesity and type 2 diabetes are also involved in autoimmunity, suggesting that metabolic syndrome may be a form of autoimmune disease.

"I'm very close to thinking of the events surrounding obesity as true autoimmunity, involving all elements of the immune system," said Dosch.

"These studies provide preclinical data that demonstrate that anti-CD3 could be efficacious for treatment of metabolic syndrome associated with type 2 diabetes," said Douglas Ringler, cofounder and CEO of Tolerx. Tolerx's otelixizumab, a mAb against CD3, is in Phase III trials for type 1 diabetes, in partnership with BTG plc and GlaxoSmithKline plc.

Ringler said the results published by Mathis and Dosch collectively argue that, like type 1 diabetes, type 2 disease could be treated by "immune reprogramming, with the common denominator of inducing regulatory T cells over potentially pathogenic Th1 cells."

The challenge, he told SciBX, will be to "overcome the dogma that metabolic syndrome and type 2 diabetes are purely biochemical and to convince people that the immune system plays an important role in their progression."

MacroGenics CEO Scott Koenig said the studies are an advance in understanding the role of inflammation in obesity but added that he wants to "get a better understanding of how the human disease and mouse models relate."

Koenig suggested that the researchers isolate the specific subpopulations of $\mathrm{T}_{\text {regs }}$ and Th1 cells that regulate adipose inflammation and then examine how these cells behave over time in obese humans. Identifying early markers of adipose inflammation could help to identify obese patients who are most at risk for inflammation-related type 2 diabetes, he noted.

MacroGenics' teplizumab anti-CD3 mAb is in Phase II/III trials for type 1 diabetes. The antibody is partnered with Eli Lilly and Co.

Other CD3 mAbs for autoimmune conditions include NovImmune S.A.'s NI-0401, which is in Phase II testing for type 1 diabetes and Crohn's disease (CD), and Johnson \& Johnson's hOKT3, which is in Phase II trials for type 1 diabetes.

Dosch thinks the strategy of targeting Th1 cells to treat obesityrelated type 2 diabetes is ready for clinical testing. "I don't think there 
are any hurdles for going into humans," he said. Indeed, Dosch has founded a virtual company, Afference Therapeutics Inc., and is seeking investors and partners to treat type 2 diabetes with anti-CD3 antibodies.

\section{Macrophage rage}

Meanwhile, two more Nature Medicine studies identified other immune cells that may respond to T cell cues to drive adipose tissue inflammation.

A team led by Satoshi Nishimura, assistant professor of cardiovascular medicine at University of Tokyo, found that $\mathrm{CD}^{+}$cytotoxic $\mathrm{T}$ lymphocytes (CTLs) accumulate in adipose tissue during obesity and help recruit macrophages, the cell type most directly linked with inflammation. ${ }^{3}$

Nishimura's group monitored the immune

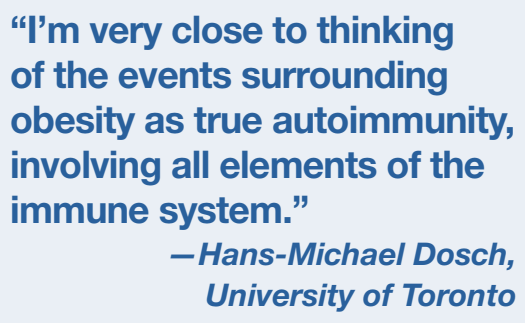

quiescent state and are thus well-placed to trigger the inflammatory cascade. "Mast cells could be the key since they are present in adipose tissue from lean people as well," he said.

However, it remains to be seen whether mast cells become activated when $\mathrm{T}_{\text {regs }}$ exit fat cells or vice versa. It is also unclear why dampening inflammation by blocking mast cell activation prevented obesity in Shi's study, whereas in the other three studies dampening inflammation by blocking macrophages and T cells did not.

Shi plans to test the effect of blocking mast cell activation in primate models of obesity and type 2 diabetes. The approach has been patented by Brigham and Women's Hospital and is being licensing to an undisclosed company in Cambridge, Mass.

MacroGenics' Koenig thinks the ultimate trigger for adipose inflammation could be an cell composition of adipose tissue in both overfed wild-type mice and genetically obese mice and observed similar changes in T cell composition as the Dosch and Mathis teams. But Nishimura also saw that CTL and macrophage levels rose as obesity progressed.

His team used an antibody to deplete $\mathrm{CD} 8^{+}$cells from obese mice and found that although body weight did not change, levels of macrophages and inflammatory cytokines dropped and insulin responsiveness improved compared with those in mock-treated controls.

Nishimura's study suggests that CTLs arrive on the scene earlier than macrophages. In other tissues, macrophages are typically the first responders.

"It was a surprise that $\mathrm{CD}^{+}$cells were increased before infiltration by macrophages," Nishimura told SciBX.

However, it remains unclear whether CTLs precede or follow the T cell changes found by Mathis and Dosch. Nishimura's next step is to identify the cytokines or other factors that recruit CTLs to the adipocytes of overfed mice.

"The molecules that attract and activate CTLs are unknown but might be the key when considering therapies," he noted.

Nishimura has not patented his findings.

\section{Mastering inflammation}

The final Nature Medicine paper suggests that the earliest players in obesity and diabetes may in fact be mast cells. ${ }^{4}$

A team led by Guo-Ping Shi, assistant professor of medicine at Harvard Medical School, confirmed that mast cell numbers were higher in the adipose tissue of obese mice and humans compared with lean controls. Shi's team then genetically eliminated mast cells but not other innate immune cells in mice. Compared with wild-type controls, mice without mast cells had less weight gain and insulin resistance when fed a high-fat diet.

The group found similar results in mice treated with two compounds known to prevent mast cell activation: a research compound, disodium cromoglycate, and ketotifen, an antihistamine marketed for ophthalmic indications.

Shi believes that mast cells ordinarily reside in adipose tissue in a as-yet unidentified antigen derived from an adipocyte protein or from a viral or bacterial agent.

"What is the antigen here? Could it be that some of the adipocytes are dying and exposing self-antigens? Or could it be that there's a pathogen?" Koenig asked.

To answer his questions, he thinks isolating the $\mathrm{T}$ cell receptors of $\mathrm{T}$ cells in inflamed adipose tissue and using them to fish out the proteins to which they bind could identify the mystery antigen.

Osherovich, L. SciBX 2(31); doi:10.1038/scibx.2009.1198

Published online Aug. 13, 2009

\section{REFERENCES}

1. Feuerer, M. et al. Nat. Med.; published online July 26, 2009; doi:10.1038/nm.2002

Contact: Diane Mathis, Harvard Medical School, Boston, Mass. e-mail: dm@hms.harvard.edu

2. Winer, S. et al. Nat. Med.; published online July 26, 2009;

Contact: Hans-Michael Dosch, The Hospital for Sick Children, Toronto, Ontario, Canada e-mail: michael.dosch@mac.com

3. Nishimura, S. et al. Nat. Med.; published online July 26, 2009; doi:10.1038/nm.1964

Contact: Satoshi Nishimura, The University of Tokyo, Tokyo, Japan e-mail: snishi-tky@umin.ac.jp

4. Liu, J. et al. Nat. Med.; published online July 26, 2009; doi:10.1038/nm.1994

Contact: Guo-Ping Shi, Brigham and Women's Hospital, Boston, Mass. e-mail: gshi@rics.bwh.harvard.edu

5. Osherovich, L. SciBX 1(24); doi:10.1038/scibx.2008.567

\section{COMPANIES AND INSTITUTIONS MENTIONED}

Afference Therapeutics Inc., Toronto, Ontario, Canada Brigham and Women's Hospital, Boston, Mass.

BTG plc (LSE:BGC), London, U.K.

Eli Lilly and Co. (NYSE:LLY), Indianapolis, Ind.

GlaxoSmithKline plc (LSE:GSK; NYSE:GSK), London, U.K.

Harvard Medical School, Boston, Mass.

The Hospital for Sick Children, Toronto, Ontario, Canada

Johnson \& Johnson (NYSE:JNJ), New Brunswick, N.J.

MacroGenics Inc., Rockville, Md.

NovImmune S.A., Geneva, Switzerland

Tolerx Inc., Cambridge, Mass.

The University of Tokyo, Tokyo, Japan

University of Toronto, Toronto, Ontario, Canada doi:10.1038/nm.2001 